\title{
A aula de Língua Portuguesa como um espaço de promoção do letramento digital: uma proposta de trabalho com o gênero discursivo "meme"
}

\author{
Juliana Fogaça Sanches Simm* \\ Antonio Lemes Guerra Junior** \\ Ednéia de Cássia Santos Pinho*** \\ Eliza Adriana Sheuer Nantes****
}

Resumo

O objetivo deste artigo é ilustrar a possibilidade de mobilização das tecnologias digitais de informação e comunicação, no âmbito do ensino de Língua Portuguesa, com vistas à promoção do letramento digital. Para isso, é apresentada uma proposta de trabalho, baseada na abordagem do gênero discursivo "meme", em aulas voltadas a uma turma do $8^{\circ}$ ano do Ensino Fundamental II. Metodologicamente, procedeu-se a uma observação assistemática das aulas conduzidas sob os fundamentos teóricos-metodológicos da Linguística Aplicada e sob o amparo das pesquisas recentes sobre as intersecções entre ensino e tecnologia. Os resultados alcançados apontam para a proficuidade da presença, na sala de aula, dos gêneros emergentes dos ambientes hipertextuais, uma vez que se percebe o maior engajamento dos estudantes nas atividades, bem como o desenvolvimento de sua postura crítica frente às práticas sociais contemporâneas.

Palavras-chave: letramento digital, ensino, tecnologia, meme.

The Portuguese language class as a space for the promotion of digital literacy: a proposal of work with the discursive genre "meme"

\begin{abstract}
The objective of this article is to discuss the possibility of mobilization of digital information and communication technologies, in the scope of Portuguese language teaching, with a view to promoting digital literacy. For this, it presents a proposal of work, based on the approach of the discursive genre "meme", in classes directed to a group of the 8th year of elementary school. Methodologically, there was an unsystematic observation of the classes, conducted under the theoretical and methodological foundations of Applied Linguistics, and based on recent research on the intersections between teaching and technology. The results show the proficuity of the presence, in the classroom, of genres emerged from the hypertextual environments, once a students' greater engagement in the activities is perceived, as well as the development of their critical attitude towards contemporary social practices.
\end{abstract}

Keywords: digital literacy, teaching, technology, meme.

\footnotetext{
* Doutora em Estudos da Linguagem. Universidade Pitágoras Unopar (UNOPAR). E-mail: julianafogacasanches@gmail.com.

** Doutor em Estudos da Linguagem. Universidade Estadual do Paraná (UNESPAR). E-mail: junior.guerra@hotmail.com.

*** Doutora em Estudos da Linguagem. Universidade Estadual de Londrina (UEL). E-mail: ediuel@yahoo.com.br.

**** Doutora em Estudos da Linguagem. Universidade Pitágoras Unopar (UNOPAR/PPGENS). E-mail: elizanantes@gmail.com.
} 


\section{Introdução}

Uma aula de Língua Portuguesa não é mais, já há algum tempo, um espaço apenas para a abordagem sistemática da língua e do texto. Trata-se, muito além disso, de um grande território de abordagem de linguagens e de textos, em sua essência plural e dinâmica. Afinal, o ensino, de uma forma geral, tem sido convocado a ingressar na era dos multiletramentos (ROJO, 2012), em que se deve buscar o preparo dos alunos para sua efetiva participação nas práticas sociais, balizadas pela multiplicidade de culturas e, também, de linguagens.

Nesse contexto, emergem inúmeros tipos de letramento, dentre os quais se destacam os letramentos digitais (DUDENEY; HOCKLY; PEGRUM, 2016), diretamente ligados à formação dos indivíduos para a execução de ações além da leitura e da escrita (eixos norteadores básicos do ensino de Língua Portuguesa), como a navegação na web, a criação e a edição de textos em novos e diferentes suportes (do papel para a tela), enfim, a circulação entre as infindáveis conexões hipertextuais que se desdobram no ciberespaço.

Diante disso, este trabalho está pautado no objetivo de ilustrar a possibilidade de mobilização das tecnologias digitais de informação e comunicação (TDIC), no âmbito do ensino de Língua Portuguesa, com vistas à promoção do letramento digital, por meio da apresentação de uma proposta de trabalho envolvendo o gênero discursivo "meme". Tal proposta direcionada a alunos das séries finais do Ensino Fundamental é aqui tomada como apenas um dos inúmeros exemplos de abordagem dos textos contemporâneos, os quais exigem das salas de aula sua abertura para novas linguagens.

Assim, para o alcance de seu objetivo, o trabalho está organizado da seguinte forma: inicialmente, é trazida a fundamentação teórica que sustenta as discussões propostas pelos autores; na sequência, são indicados os procedimentos metodológicos que balizaram a execução da pesquisa; depois, os resultados são apresentados e analisados; e, por fim, são tecidas as considerações finais decorrentes do processo de investigação. 


\section{Fundamentação teórica}

A partir do objetivo delineado para este trabalho, conforme apresentado no item introdutório, a fundamentação teórica que sustenta as proposições aqui empreendidas é conduzida a partir de um percurso gradativo, conforme sintetiza a Figura 1, a seguir:

Figura 1 - Síntese do percurso teórico do trabalho.

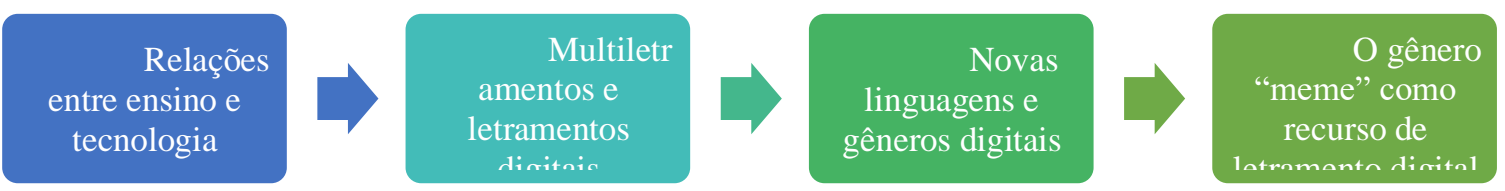

Fonte: os autores.

\section{Relações entre ensino e tecnologia}

Nos últimos anos, tem-se percebido um movimento direcionado à abertura dos espaços escolares a uma ampla rede de recursos, decorrentes, em especial, da emergência das TDIC. Tal movimento se sustenta numa premissa básica: "educação e tecnologia são indissociáveis" (KENSKI, 2015a, p. 43). Assim, se a tecnologia não para de evoluir, a escola não pode manter-se estagnada.

A recomendação para que recursos tecnológicos digitais estejam presentes nas salas de aula é evocada, também, na Base Nacional Comum Curricular (BNCC), em uma de suas dez competências gerais para a Educação Básica, segundo a qual, espera-se preparar o aluno para:

\footnotetext{
Compreender, utilizar e criar tecnologias digitais de informação e comunicação de forma crítica, significativa, reflexiva e ética nas diversas práticas sociais (incluindo as escolares) para se comunicar, acessar e disseminar informações, produzir conhecimentos, resolver problemas e exercer protagonismo e autoria na vida pessoal e coletiva (BRASIL, 2017, p. 9).
}

Isso provoca um repensar da prática pedagógica, pois, conforme Kenski (2015b, p. 30), "as velozes transformações tecnológicas da atualidade impõem novos ritmos e dimensões à tarefa de ensinar e aprender”, o que exige de todos - alunos e professores a predisposição para um "permanente estado de aprendizagem e de adaptação ao novo". 
Afinal, "novas tecnologias e velhos hábitos de ensino não combinam” (KENSKI, 2015b, p. 75).

Nesse novo cenário de efervescentes transformações, não basta mais apenas "letrar", ensinar a ler e a escrever, competências básicas do sujeito dito "letrado". Falase, hoje, no desafio de "multiletrar".

\section{Multiletramentos e letramentos digitais}

A escola contemporânea evidencia-se como um palco de multiplicidades - de culturas e de linguagens -, e a sua abordagem, conforme Rojo (2012, p. 19), demanda "capacidades e práticas de compreensão e produção de cada uma delas para fazer significar”. Essas "capacidades e práticas”, os chamados "multiletramentos”, configuram uma pedagogia pautada na inclusão, no currículo escolar, de diferentes estratégias de preparo dos estudantes para as práticas sociais da atualidade.

Manusear suportes para além do papel, percorrer telas, acessar links, estabelecer multiconexões no ciberespaço estão entre tarefas básicas a integrarem o rol dos multiletramentos, dentre os quais ganham ênfase os letramentos digitais, definidos por Dudeney, Hockly e Pegrum (2016, p. 17) como "habilidades individuais e sociais necessárias para interpretar, administrar, compartilhar e criar sentido eficazmente no âmbito crescente de comunicação digital".

E tais letramentos são cada vez mais necessários, uma vez que, junto aos recursos digitais, "surgem novas formas de ser, de se comportar, discursar, de se relacionar, de se informar, de aprender", exigindo que os alunos - como quaisquer indivíduos de hoje estejam aptos para "novos tempos, novas tecnologias, novos textos, novas linguagens" (ROJO; BARBOSA, 2015, p. 116).

\section{Novas linguagens e gêneros digitais}

A linguagem é a base dos processos interacionais, sendo concebida, inclusive, como um "lugar de interação" $(\mathrm{KOCH}, 1992)$. É por meio dela que se constroem os textos, os quais, por sua vez, materializam os gêneros discursivos, "tipos relativamente 
estáveis de enunciados" (BAKHTIN, 2003, p. 262), que permitem a reiteração dos discursos, por meio de estruturas composicionais mais ou menos regulares.

Ao passo que a linguagem se manifesta de formas diferentes, desdobrando-se em uma pluralidade de "linguagens", verbais, não verbais, multimodais ou multissemióticas, os gêneros discursivos passam também a dar origem a novos textos, marcados por novos modos de significação - os textos multimodais (ROJO, 2012).

Nesse contexto, conforme Rojo (2013, p. 8), vale destacar que,

Se os textos da contemporaneidade mudaram, as competências / capacidades de leitura e produção de textos exigidas para participar de práticas de letramento atuais não podem ser as mesmas. Hoje, é preciso tratar da hipertextualidade e das relações entre diversas linguagens que compõem um texto, o que salienta a relevância de compreender os textos da hipermídia.

E, para lidar com a hipertextualidade, com o hipertexto, "uma forma híbrida, dinâmica e flexível de linguagem que dialoga com outras interfaces semióticas, adiciona e acondiciona à sua superfície formas outras de textualidade" (XAVIER, 2010, p. 208), é essencial a mobilização de suportes hipermidiáticos, como as redes sociais, nas quais circulam novos gêneros discursivos, hoje também recobertos pela propriedade "digital", como o "meme".

\section{O gênero "meme" como recurso de letramento digital}

$\mathrm{Na}$ atualidade, o termo "meme" caracteriza o nome dado a um gênero discursivo digital, concretizado por meio de textos típicos da internet, marcados, em síntese, pela sobreposição de frases a imagens extraídas de diferentes contextos (filmes, programas de TV, fotografias, etc.), gerando um efeito de humor que lhes é característico, o qual pode ser permeado, por vezes, por uma tonalidade crítica, irônica, ácida, satírica ou sarcástica.

Conforme Machado (1999, p. 43), "a palavra meme foi criada a partir de uma corruptela da palavra grega mímesis (imitação)", sendo concebida originalmente na obra O gene egoísta (1976), do biólogo e escritor britânico, Richard Dawkins, especialmente no capítulo "Memes: os novos replicadores", de modo a referir-se a um "replicador", uma "unidade de transmissão cultural, ou uma unidade de imitação" (DAWKINS, 1979, p. 214). 
Os memes podem ter exemplos encontrados em melodias, slogans, recursos da moda, procedimentos, ideias transmitidas de uma pessoa a outra (DAWKINS, 1979). Nas palavras de Dawkins (1979, p. 214), "se a idéia pegar, pode-se dizer que ela se propaga a si própria, espalhando-se de cérebro a cérebro". E é justamente na propagação que está a essência do meme concebido como um gênero discursivo: alguém o cria, posta-o numa rede social, alguns curtem, outros compartilham, e ele, numa velocidade "internética", propaga-se, carregando consigo o seu conteúdo.

Ao se propagar, junto ao seu conteúdo, o meme tende a disseminar, em geral, o resultado de uma leitura crítica do mundo, denunciando realidades, opondo-se a elas ou, simplesmente, validando-as. Assim, considerando que, hoje, espera-se do professor um trabalho centrado "na competência estimuladora da pesquisa, incentivando com engenho e arte a gestação de sujeitos críticos e autocríticos, participantes e construtivos" (DEMO, 2006, p. 103), o meme se torna um objeto de ensino-aprendizagem inescapável.

Por meio da abordagem do meme, torna-se possível, ao mesmo tempo: (i) discutir o conceito de gênero e sua estrutura composicional; (ii) contemplar aspectos multimodais e hipertextuais das linguagens contemporâneas; (iii) incentivar e refinar o posicionamento crítico dos estudantes; (iv) e, devido ao fato de sua criação, sua circulação e sua recepção serem balizadas pelas TDIC, promover o letramento digital.

É com base nessas possibilidades que se desenha a proposta apresentada a seguir.

\section{Metodologia}

Por um viés predominantemente qualitativo, a investigação aqui empreendida pauta-se pela tentativa de compreensão do espaço "aula de português" como um cenário propício para a abordagem de gêneros digitais - como o meme - e, consequentemente, para a promoção do letramento digital dos alunos. Em síntese, busca-se evidenciar possibilidades de preparo dos estudantes para o uso da linguagem em novas configurações das práticas sociais.

Assim, metodologicamente, por suas especificidades, o trabalho foi desenvolvido sob o escopo da Linguística Aplicada, compreendida como "uma área de investigação interdisciplinar que se centra na resolução de problemas da prática de uso da linguagem 
dentro e fora da sala de aula", com ênfase na investigação de "problemas de uso da linguagem situados em contextos da práxis humana" (MOITA-LOPES, 1996, p. 3).

No que tange à proposta didático-pedagógica selecionada para este trabalho, são evocados os preceitos da Pedagogia Histórico-Crítica (PHC), que propõem a "conversão do saber objetivo em saber escolar, de modo que se torne assimilável pelos alunos no espaço e tempo escolares" (SAVIANI, 1991, p. 16), no caso, a utilização de um gênero comum ao cotidiano do aluno (portanto, um saber objetivo), mas de modo sistematizado, com vistas ao seu letramento digital (um saber escolar).

Para isso, foi mobilizado o aparato teórico-metodológico do Plano de Trabalho Docente (PTD), conforme proposto por Gasparin (2002) e referendado pelas Diretrizes Curriculares do Estado do Paraná - DCE (PARANÁ, 2008), com base nas reflexões de Saviani (1991), por meio do desenvolvimento de um percurso balizado pela sequência "prática > teoria > prática", com a abordagem do conhecimento não sistematizado, passando por seu tratamento e, por fim, sua conversão em conhecimento transformado e aplicável na realidade.

Desse modo, considerando os passos descritos por Gasparin (2002) para a execução do PTD, conforme Quadro 1, foram delineadas estas ações:

Quadro 1 - Síntese metodológica do PTD da proposta

\begin{tabular}{|l|l|}
\hline Prática social inicial & $\begin{array}{l}\text { Identificação do conhecimento dos estudantes sobre memes e exploração de } \\
\text { ambientes virtuais. }\end{array}$ \\
\hline Problematização & Reflexão sobre o papel social dos memes nos ambientes em que circulam. \\
\hline Instrumentalização & $\begin{array}{l}\text { Promoção de ações didático-pedagógicas voltadas à abordagem do gênero "meme” } \\
\text { (conteúdo temático, construção composicional e estilo linguístico). }\end{array}$ \\
\hline Catarse & $\begin{array}{l}\text { Debate sobre o uso consciente e efetivo dos memes nas práticas sociais } \\
\text { contemporâneas. }\end{array}$ \\
\hline Prática social final & $\begin{array}{l}\text { Criação e compartilhamento de memes baseados em noticiários com vistas ao } \\
\text { posicionamento crítico dos alunos acerca de sua realidade. }\end{array}$ \\
\hline
\end{tabular}

Fonte: os autores, com base em Gasparin (2002) e Paraná (2008).

O PTD sintetizado no Quadro 1 foi tomado como base para a condução de um trabalho desenvolvido em uma turma do $8^{\circ}$ ano do Ensino Fundamental II, de um colégio da rede pública estadual, na cidade de Londrina - PR, campo de atuação docente de um dos autores do trabalho. Ao todo, a execução da proposta contemplou um total de quatro aulas, envolvendo a participação de aproximadamente 30 alunos nas atividades, além de 
contar com a supervisão/observação de integrantes do projeto de pesquisa ${ }^{1}$ do qual faz parte a professora-pesquisadora.

O desdobramento do PTD ao longo dos quatro encontros foi assim realizado:

- Aula 1: Prática social inicial + Problematização

- Aula 2: Instrumentalização + Catarse

- Aulas 3 e 4: Prática social final
| conhecimento não sistematizado | teorização do conhecimento

| conhecimento sistematizado

Os dados selecionados para este trabalho resultam de uma observação não estruturada ou assistemática (MARCONI; LAKATOS, 2003), caracterizada pela não mobilização de meios técnicos especiais. Trata-se de dados decorrentes da aplicação do PTD ao longo dos encontros descritos, marcados pela convergência das percepções tanto da professora-pesquisadora, responsável pela aplicação da proposta, quanto dos demais pesquisadores envolvidos, colaboradores no processo de elaboração do PTD.

Assim, na seção a seguir, é apresentada uma breve descrição dos quatro encontros voltados à aplicação do PTD, com o registro das ações empreendidas, bem como a análise de algumas das produções dos alunos, as quais, à luz do aporte teórico que sustenta o trabalho, serão tomadas como elementos principais para o alcance do objetivo previamente delineado - ilustrar a possibilidade de mobilização das TDICs, no ensino de Língua Portuguesa, com vistas à promoção do letramento digital.

\section{Resultados e discussão}

Conforme descrito na apresentação dos procedimentos metodológicos do trabalho, a proposta tomada como base para as análises envolve a aplicação de um PTD, a partir das indicações de Gasparin (2002), em um conjunto de quatro encontros, cujas especificidades são descritas a seguir:

\section{Aula 1 - abordagem do conhecimento não sistematizado}

Para a "prática social inicial", situando a proposta em um cenário típico para a promoção dos letramentos digitais (cf. DUDENEY; HOCKLY; PEGRUM, 2016), os

\footnotetext{
${ }^{1}$ Projeto "Ensino, tecnologia e linguagens: uma investigação dos aspectos teóricos e metodológicos para promoção dos letramentos digitais", desenvolvido na Universidade Pitágoras Unopar.
} 
alunos foram levados à sala de multimeios ${ }^{2}$ da escola, onde, primeiramente, foi realizada uma sondagem a respeito do conhecimento que tinham sobre o gênero "meme". Para isso, a professora realizou diversos questionamentos, tais como: O que é um meme? Onde circula? Quem são os produtores desse tipo de texto? Qual a finalidade do gênero?

De acordo com relatos da regente, vários alunos, de início, não souberam dizer o que é um meme, por desconhecerem a nomenclatura atribuída a textos desse gênero. No entanto, após a apresentação de um exemplo, imediatamente, todos demonstraram ter algum conhecimento sobre ele, apontando várias de suas características e os meios onde circula. Nesse momento, inclusive, demonstraram curiosidade no que tange à autoria, questionando quem seriam os possíveis produtores desse tipo de gênero, uma vez que, na maioria das vezes, trata-se de textos virais e, comumente, não trazem marcas de autoria, podendo ter sua criação atribuída a qualquer pessoa.

Após esse primeiro momento, a professora efetuou o segundo passo previsto no PTD: a "problematização". Assim, por meio da exploração desse gênero, os alunos foram levados a refletir sobre como os textos que o materializam estão inseridos nas práticas sociais, reconhecendo seus contextos de circulação, sobretudo os relacionados às redes sociais, ambientes propícios para a abordagem das manifestações hipertextuais (cf. XAVIER, 2010). Além disso, ao averiguarem as temáticas contempladas, verificaram que tais textos, para além da função humorística, atendem a uma importante função social, que é a de clarificar o cenário político, social e cultural da realidade em que vivem.

\section{Aula 2 - teorização do conhecimento}

Nessa aula, visando ao terceiro passo do PTD, a "instrumentalização" dos alunos, a professora realizou uma abordagem teórica do gênero "meme", em relação ao seu conteúdo temático, à sua construção composicional e ao seu estilo linguístico (cf. BAKHTIN, 2003). Assim, ainda na sala de multimeios, a professora apresentou de forma sistematizada a origem e o conceito de "meme" (cf. DAWKINS, 1979) e, em seguida, apresentou vários exemplos para que os estudantes pudessem elencar as possibilidades temáticas desse gênero.

\footnotetext{
${ }^{2}$ Espaço da escola utilizado para aulas diferenciadas, em que ficam à disposição de alunos e professores: tela, projetor de slides, sistema de áudio.
} 
Desse modo, a partir da análise de alguns textos e por meio da mediação da regente, eles verificaram que, de forma geral, os memes podem explorar temas políticos, econômicos e cotidianos, estabelecendo relações intertextuais e interdiscursivas com discursos em voga na atualidade. Além disso, foram contempladas as associações estabelecidas entre as linguagens verbal e não verbal (a multimodalidade, cf. ROJO, 2012), o uso de ironias, o emprego de linguagem informal e os procedimentos envolvidos na interpretação crítica desses textos.

Alicerçados pelas etapas anteriores, os alunos chegaram à fase da "catarse", na qual ressignificaram o conceito a respeito do gênero estudado. A partir das discussões empreendidas em sala, no formato de um debate, passaram a compreender que, para além do entretenimento, os memes possuem uma importante função na sociedade atual: por serem virais, fazerem uso de imagens e serem relacionados à cultura pop, possibilitam que as informações repercutam com mais rapidez, com uma "atualização" constante das narrativas políticas e sociais vigentes no cenário contemporâneo, facilitando a compreensão da realidade que os cerca.

\section{Aulas 3 e 4 - reorganização e aplicação do conhecimento}

Após profícua abordagem do conteúdo temático, da construção composicional, do estilo linguístico (cf. BAKHTIN, 2003) e, principalmente, da função social do gênero “meme”, foi possível avançar para a fase seguinte do PTD, ou seja, a "prática social final", momento no qual os alunos efetivamente demonstram o que aprenderam durante o processo. Assim, para essa etapa, eles foram desafiados a produzir seus próprios memes.

Para isso, a partir dos conteúdos já sistematizados a respeito do gênero, a professora passou à condução da atividade prática com os alunos. Desse modo, a turma foi encaminhada à sala de informática ${ }^{3}$ da escola, e os estudantes foram orientados a se reunir em equipes (de três ou quatro integrantes) para que pudessem, inicialmente, selecionar notícias sobre assuntos e eventos que estivessem repercutindo na época, na cidade ou no país. A organização em equipes propiciou o trabalho colaborativo, um dos

\footnotetext{
${ }^{3}$ Espaço da escola, diferente da sala de multimeios, citada na descrição das Aulas 1 e 2, em que alunos e professores têm à sua disposição computadores e conexão à internet, para o desenvolvimento de aulas e atividades.
} 
alvos das metodologias contemporâneas que buscam a promoção, também, dos multiletramentos (cf. ROJO, 2012).

Após essa etapa, como sugestão de ferramenta auxiliadora durante o processo de produção, a docente apresentou aos alunos um site, em que é possível a criação de memes ${ }^{4}$, instruindo-os para o uso adequado desse recurso. Esse momento configurou-se como um espaço para a promoção efetiva dos letramentos digitais (cf. DUDENEY; HOCKLY; PEGRUM, 2016), em que foi oportunizada aos estudantes a mobilização de competências típicas dos ambientes digitais.

$\mathrm{Na}$ aula seguinte, em continuidade à fase final do PTD, os alunos se debruçaram na seleção das imagens e na produção dos enunciados verbais que comporiam seus memes, cujo conteúdo teria que, obrigatoriamente, estar relacionado ao tema tratado nas notícias previamente escolhidas por eles para nortear o processo de criação, além de evidenciar o seu posicionamento crítico acerca da temática contemplada. Na sequência, por fim, as equipes acessaram o site criador de memes para finalizarem suas produções, compartilhando-as, depois de prontas, na pasta virtual da turma criada pela professora na plataforma Google Drive ${ }^{5}$.

Como resultado desse percurso, é apresentada a análise das produções de algumas equipes (Figuras 2, 3 e 4), com evidências da efetividade do processo, no que tange ao letramento digital dos alunos por meio do estudo de um gênero contemporâneo, o meme.

\section{Produção 1}

Meme produzido com base em notícia sobre cobranças abusivas de impostos

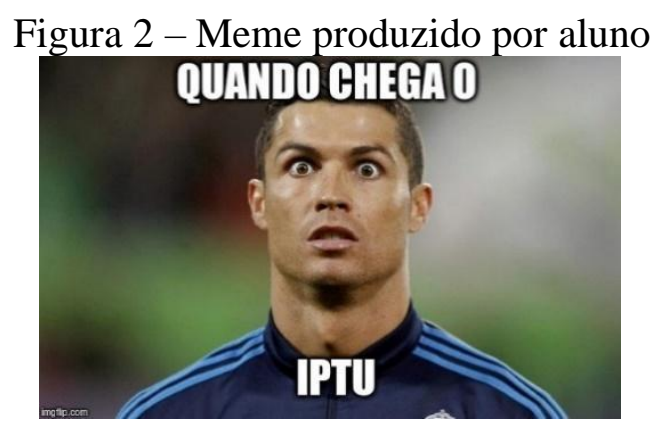

Fonte: dados da pesquisa.

\footnotetext{
${ }^{4}$ Ferramenta disponível em: https://imgflip.com/memegenerator. Acesso em: 19 jun. 2019.

${ }^{5}$ Plataforma disponibilizada pelo Google e amplamente utilizada para o compartilhamento de arquivos e para o desenvolvimento de trabalhos colaborativos.
} 
O meme (produção 1) mescla a linguagem verbal e a imagética - numa composição multimodal (cf. ROJO, 2012) - em favor de uma construção que evidencia o contexto de cobrança do chamado Imposto Predial e Territorial Urbano (IPTU). Para produzir efeito de sentido, a escolha da imagem do jogador de futebol conhecido internacionalmente, Cristiano Ronaldo, expressando espanto é determinante, pois os olhos arregalados e fixos do jogador ratificam a ideia de susto, assombro. Atrelado à linguagem não verbal está o enunciado "Quando chega o IPTU”, que relaciona, de forma inegável, o contexto da cobrança à indignação "do jogador" - reação que, numa acepção mimética detectada na origem do termo "meme" (cf. MACHADO, 1999), representaria a reação do cidadão comum.

Fica evidente, nessa construção, o posicionamento dos alunos frente à situação de cobrança abusiva de impostos na qual os londrinenses estavam envolvidos. Para fins contextuais, é válido ressaltar que a cidade de Londrina - PR, na época, passava por um momento turbulento na cobrança do IPTU, que encareceu muito de 2017 para 2018, fato que gerou inúmeras críticas e questionamentos direcionados às autoridades públicas, pois o aumento foi muito além do que era esperado pelos munícipes. Dessa forma, no noticiário da cidade, diversas reportagens circulavam cotidianamente e tornavam recorrentes as discussões sobre o assunto.

Fica claro, portanto, que os alunos, embora não pertencentes à faixa etária envolvida diretamente no pagamento da referida taxa, estavam atentos a essa conjuntura político-social. Essa situação, por sua vez, serviu-lhes de inspiração na escolha de uma notícia relacionada ao tema para a base da produção de seu meme, gênero com o qual têm intenso contato nas redes sociais (em especial, o Facebook). Isso permitiu-lhes manifestar sua crítica, enquanto cidadãos que sentem e compreendem a realidade social que os circunda, evidenciando, assim como nas demais produções a seguir, a possibilidade de “gestação de sujeitos críticos” em sala de aula (cf. DEMO, 2006). 


\section{Produção 2}

Meme produzido com base em noticia sobre reforma da Previdência

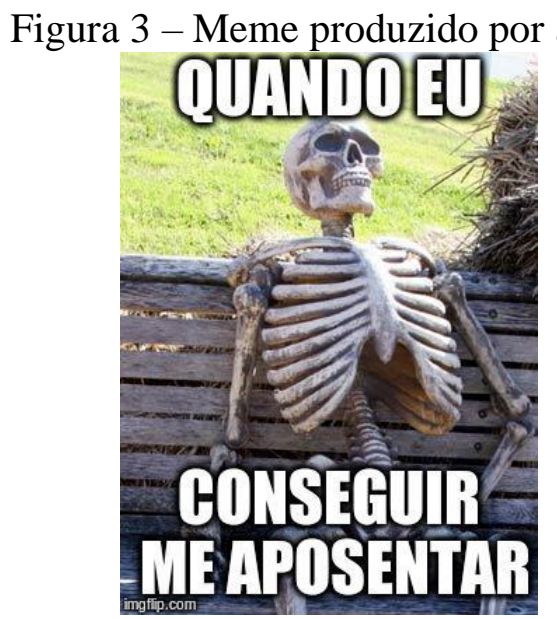

Fonte: dados da pesquisa.

A produção do segundo meme é pautada, também, na junção da imagem e do texto escrito, essência dos textos multimodais (cf. ROJO, 2012), especialmente no âmbito da hipertextualidade (cf. XAVIER, 2010). Nesse sentido, relacionam-se com igual força argumentativa e expressão de sentido a construção verbal "Quando eu conseguir me aposentar" e a figura do esqueleto, uma vez que, isoladas, as linguagens não provocariam o efeito almejado.

Faz parte do conhecimento de mundo da maioria dos indivíduos, e nesse grupo incluem-se os estudantes do $8^{\circ}$ ano responsáveis pela criação desse meme, que os ossos sustentam o corpo humano, e que sua decomposição leva muito mais tempo do que a da pele e das vísceras. Obviamente, também, não é possível que um esqueleto sozinho seja capaz de manter-se sentado em um banco, como se estivesse à espera de algo ou alguém. Entretanto, é justamente esta a ideia que os alunos quiseram enfatizar: uma longa espera, sem perspectiva, que ultrapassa o período de vida humana ativa.

A Reforma da Previdência, pauta que recentemente tem circulado com frequência no meio governamental, no geral, é de interesse de todo cidadão em idade laboral, ou seja, acima dos 16 anos. Entretanto, com a criação desse meme, os alunos demonstraram um forte engajamento com as questões sociais que circulam no país, além de evidenciar senso crítico apurado frente à realidade brasileira, no que tange ao direito à aposentadoria. 
Assim, constata-se que foi atingido o objetivo de levar os discentes à reflexão sobre sua própria realidade, posicionando-se como indivíduos socialmente permeados por múltiplas culturas e linguagens, em consonância com a pedagogia dos multiletramentos (cf. ROJO, 2012). Ademais, um gênero de intensa circulação contemporânea, fruto das novas conformações tecnológicas e comunicativas, foi mobilizado de modo coerente e assertivo, a fim de atingir seu propósito: evidenciar, de forma crítica e satírica, um aspecto da realidade social a partir de atualidades.

\section{Produção 3}

Meme produzido com base em notícia sobre a corrupção no país

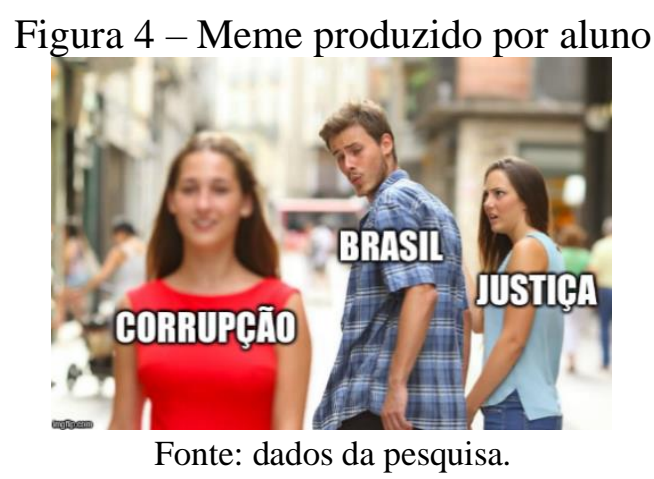

A terceira produção, embora também apresente como caráter motivador as notícias divulgadas, na época, sobre corrupção no país, possibilita inferências mais profundas e atemporais. A seleção lexical dos substantivos "corrupção", "Brasil” e "justiça", empreendida pelos estudantes, não chega a constituir uma frase, em uma acepção gramatical, sintática, porém sua escolha não é aleatória, principalmente quando atrelada à posição e ao semblante dos personagens.

Nessa produção, pode-se inferir a construção de uma breve cena do cotidiano, na qual se encontra um casal, de mãos dadas, andando pela rua de uma cidade, sendo que o rapaz, em determinado momento, é atraído pela beleza de outra mulher caminhando em direção oposta. O frame capta o instante exato em que ele volta o seu olhar para ela, de forma desrespeitosa, ignorando a presença de sua companheira. Essa atitude é vista de modo negativo e, até mesmo, com perplexidade pela namorada/esposa, o que se comprova por sua expressão facial. É essa disposição de movimentos que estabelece a conexão 
semântica entre os elementos verbais, evidenciando a convergência de linguagens para a construção do sentido no texto multimodal (cf. ROJO, 2012).

Ao se analisar a junção de todos esses elementos na construção dos sentidos pretendidos, chega-se à interpretação de que, na visão dos alunos, a corrupção (representada pela moça de vermelho) é atrativa, bela, chama a atenção e faz com que o indivíduo (representado pelo rapaz de camisa xadrez) ignore a presença da justiça (representada pela moça de azul, companheira do rapaz). Com isso, de modo incontestável, a produção dos alunos materializa o status de "replicador cultural" atribuído originalmente ao meme (cf. DAWKINS, 1979).

Em síntese, de modo crítico, os alunos procuraram mostrar que, na sua concepção, a corrupção se mistura com a história e a cultura da nação brasileira, uma vez que atrai, desde sempre, tanto os indivíduos em situações comuns do cotidiano quanto os líderes do alto escalão do governo. Entre a escolha de permanecer ao lado da honestidade ou da corrupção, encontra-se a justiça, que, muitas vezes, não é capaz de inibir aqueles que pretendem se aproximar da ilicitude.

\section{Considerações finais}

Esta pesquisa teve início com o intuito de apontar possibilidades de trabalho, contemplando as TDICs como recursos pedagógicos a serem explorados na esfera escolar. Enquanto recorte, a proposta foi direcionada para o ensino de Língua Portuguesa, no $8^{\circ}$ ano do Ensino Fundamental II, visto que a professora regente integra o grupo de pesquisadores autores deste trabalho, participando das discussões sobre a premência do diálogo entre ensino $\leftrightarrow$ multiletramentos $\leftrightarrow$ tecnologia $\leftrightarrow$ letramentos digitais.

Para a transposição do constructo teórico à prática pedagógica, considerando a localização do espaço da pesquisa na cidade de Londrina - PR, foram seguidas as proposições das Diretrizes Curriculares do Estado do Paraná (PARANÁ, 2008), com a elaboração de um PTD (cf. GASPARIN, 2002), tendo como objeto de ensino a abordagem do gênero discursivo "meme".

Assim, após análise do percurso teórico-prático, a fim de validar os dados, ao serem discutidas as produções, procedeu-se ao cruzamento dos dados com os métodos, de forma que houvesse a intersecção entre o quadro epistemológico e as atividades 
práticas realizadas pelos alunos. Isso culminou com produções de memes criativos, cujo conteúdo temático apontou a presença de questões reais, as quais permeiam o cotidiano do educando, além de terem possibilitado a promoção do desenvolvimento/aprimoramento dos letramentos digitais.

Outro ponto a ser destacado é o fato de as produções refletirem as indicações da BNCC (BRASIL, 2017), no que se refere à possibilidade/necessidade de a esfera escolar trabalhar com os eixos Análise Linguística/Semiótica e Produção Textual, de forma que o "produto" contemple as TDICs, com produções nas quais ecoe a voz do aluno, tanto pela criatividade quanto pela capacidade de reflexão sobre a realidade na qual ele está inserido.

\section{Referências}

BAKHTIN, M. Estética da criação verbal. Trad. Paulo Bezerra. 4. ed. São Paulo: Martins Fontes, 2003.

BRASIL. Ministério da Educação. Base Nacional Comum Curricular. Brasília: MEC, 2017.

DAWKINS, R. O gene egoísta. Trad. Geraldo H, M. Florsheim. Belo Horizonte: Itatiaia; São Paulo: Edusp, 1979.

DEMO, P. Formação permanente e tecnologias educacionais. São Paulo: Vozes, 2006.

DUDENEY, G.; HOCKLY, N.; PEGRUM, M. Letramentos digitais. Trad. Marcos Marcionilo. São Paulo: Parábola Editorial, 2016.

GASPARIN, J. L. Uma didática para a pedagogia histórico-crítica. 1. ed. Campinas: Autores Associados, 2002.

KENSKI, V. M. Educação e tecnologia: o novo ritmo da informação. Campinas: Papirus, 2015a.

KENSKI, V. M. Tecnologias e ensino presencial e a distância. Campinas: Papirus, $2015 b$.

KOCH, I. G. V. A inter-ação pela linguagem. São Paulo: Contexto, 1992.

MACHADO, A. Pode-se falar em gêneros na televisão? Famecos, Porto Alegre, n. 10, p. 142-158, jun. 1999. 
MARCONI, M. A.; LAKATOS, E. M. Fundamentos de metodologia científica. 5. ed. São Paulo: Atlas, 2003.

MOITA-LOPES, L. P. Contextos institucionais em Lingüística Aplicada: novos rumos. Intercâmbio, São Paulo, v. 5, p. 3-14, 1996.

PARANÁ. Secretaria de Estado de Educação. Diretrizes Curriculares da Educação Básica: Língua Portuguesa. Curitiba: SEED, 2008.

ROJO, R. Pedagogia dos multiletramentos: diversidade cultural e de linguagens na escola. In: ROJO, R.; MOURA, E. (Orgs.). Multiletramentos na escola. São Paulo: Parábola, 2012, p. 11-31.

ROJO, R. Apresentação. In: ROJO, R. (Org.). Escol@ conectada: os multiletramentos e as TICS. São Paulo: Parábola, 2013.

ROJO, R.; BARBOSA, J. P. Hipermodernidade, multiletramentos e gêneros discursivos. São Paulo: Parábola, 2015.

SAVIANI, D. Pedagogia histórico-crítica: primeiras aproximações. 1. ed. São Paulo: Cortez, 1991.

XAVIER, A. C. Leitura, texto e hipertexto. In: MARCUSCHI, L. A.; XAVIER, A. C. (Orgs.). Hipertexto e gêneros digitais: novas formas de construção do sentido. 3. ed. Rio de Janeiro, Lucerna, 2010, p. 207-220. 